\title{
Efficacy of a single measurement of plasma anti-Müllerian hormone concentration for ovum pick-up donor selection of Japanese Black heifers in herd breeding programs
}

\author{
Yasuo FUSHIMI'), Danielle MONNIAUX ${ }^{2)}$ and Mitsuhiro TAKAGI ${ }^{3)}$ \\ ${ }^{1)}$ Guardian Co. Ltd., Kagoshima 890-0033, Japan \\ 2) Physiologie de la Reproduction, Centre INRA Val de Loire, 37380 Nouzilly, France \\ 3) Joint Faculty of Veterinary Medicine, Yamaguchi University, Yamaguchi 753-8515, Japan
}

\begin{abstract}
In this study, we evaluated the efficiency of a single measurement of plasma anti-Müllerian hormone (AMH) concentration in heifers in determining the number of oocytes recoverable by ovum pick-up (OPU), and compared AMH concentrations among sister heifers from the same parents. For this, blood samples from 50 embryo-transfer-derived female Japanese Black (JB) heifers (mean: 8.7 age in months) were collected and plasma AMH concentration was measured. At 13-15 months of age, both the number of follicles $(2-9 \mathrm{~mm})$ and the number of collected oocytes after OPU were counted and compared. Results indicated that the heifers with the highest AMH concentration had the highest number of follicles in their ovaries and gave the highest number of collected oocytes with OPU, thereby indicating that a single measurement of plasma AMH concentration is informative for the selection of OPU-donor heifers in herd breeding programs. The practice of performing a single AMH measurement may accelerate the intensive breeding of JB herds.
\end{abstract}

Key words: Anti-Müllerian hormone, Cattle intensive breeding, Japanese Black cattle, Ovum pick-up

(J. Reprod. Dev. 65: 369-374, 2019)

$\mathbf{T}$ he profitability of the dairy and beef industries is highly correlated with meat and milk yield, genetic selection, and reproductive efficiency. Therefore, reproductive technologies such as in vivo or in vitro embryo production have been applied worldwide to rapidly enhance the genetics of dairy and beef cattle through the female lineage [1]. The scale-up of large-scale farming and intensive production is accelerating for many breeds including the production of Japanese Black (JB) cattle in Japan. Successful breeding cattle are increasingly important not only for traditional breeding programs but also for embryo production as excellent donors for improving breeding ability. In general, 8-10-month-old JB heifers in Japan are either sold for meat or held as egg donors for breeding. The criteria used for selecting donor heifers depends on growth rate, pedigree, market conditions, temper, and meat quality based on information from their siblings. However, considerable individual variability in the responsiveness to superovulation treatment or in the number of collected oocytes after ovum pick-up (OPU) have been reported [2-4]. Although recent reports have indicated that a single ultrasound examination of the ovaries performed at pre-pubertal ages to count antral follicles can be used as a predictor of the number of oocytes that can be collected $[5,6]$, it is difficult to conduct rectal palpation on JB heifers due to their body size at 8-9 months old. Therefore,

Received: January 12, 2019

Accepted: March 18, 2019

Published online in J-STAGE: March 30, 2019

(C)2019 by the Society for Reproduction and Development

Correspondence: M Takagi (e-mail: mtakagi@yamaguchi-u.ac.jp)

This is an open-access article distributed under the terms of the Creative Commons Attribution Non-Commercial No Derivatives (by-nc-nd) License. (CC-BY-NC-ND 4.0: https://creativecommons.org/licenses/by-nc-nd/4.0/) development of a prognostic method for determining the intrinsic capacity of a potential donor heifer to produce an expected number of oocytes or embryos is necessary.

Anti-Müllerian hormone (AMH) is a glycoprotein belonging to the transforming growth factor beta family and is secreted by ovarian granulosa cells mainly from pre-antral and early antral follicles in female [7, 8]. Recent studies have indicated that the AMH concentration in cattle is characteristic of an individual cow and that it can be considered to be a reliable endocrine marker of the number of ovulation events and embryos produced in response to superovulation or through Ovum Pick Up/In vitro Embryo Production (OPU-IVP) [5, 9-11]. Regarding JB cattle, a recent study of JB heifers revealed that circulating $\mathrm{AMH}$ concentration in heifers aged 10 or 11 months correlated with the number of embryos collected after superovulation at 13-18 months old [12]. Thus, it was concluded that the evaluation of AMH concentration during the early stage is valuable for the selection of candidate embryo donors in JB cattle [12]. Based on these findings, we speculated that a single measurement of AMH concentration in JB heifers aged approximately 9-10 months may be useful for predicting the breeding potential of OPU-donor heifers undergoing routine OPU treatment 3-4 months after the AMH measurement.

The number of blastocysts produced by OPU-IVP is dependent upon the number of recovered oocytes $[13,14]$, and the selection of donor cows for an OPU-IVP program seems to be the best approach to optimize the number of highly competent oocytes and embryos produced [14]. Thus, we carried out the present study to progress the efficiency of genetic improvement and embryo production by routine OPU trial. We selected heifers from a commercial farm based on measurements of AMH concentration. All heifers were derived 


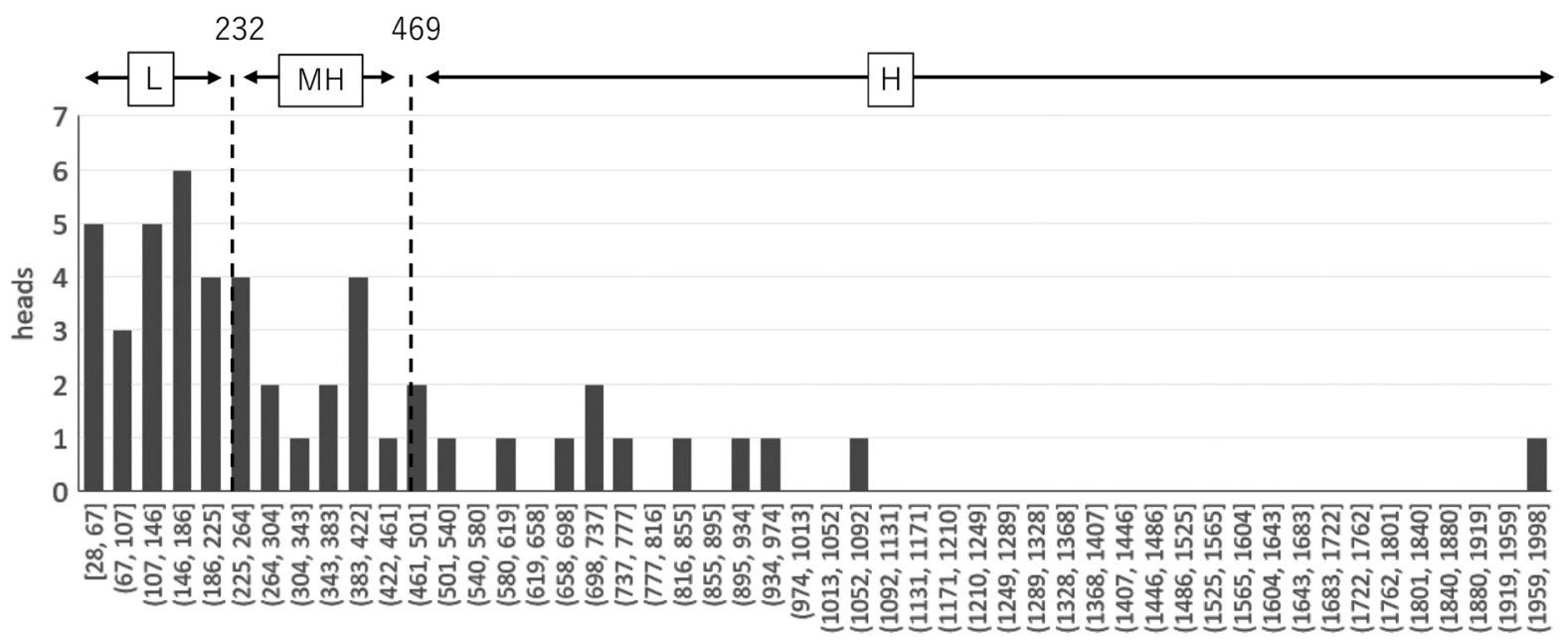

Plasma AMH concentrations $(\mathrm{pg} / \mathrm{ml})$

Fig. 1. Frequency distribution of plasma anti-Müllerian hormone (AMH) concentration ( $n=50)$. Group H: highest $25 \%$ of heifers; Group MH: next $25 \%$ of heifers; Group L: lowest $50 \%$ of heifers.

from multiple ovulation and embryo transfer (MOET) production.

The objective of the present study was to evaluate the relationship between a single plasma AMH concentration measurement in heifers aged approximately 7-10 months and the number of oocytes recovered after OPU treatment at 13-15 months of age. Additionally, AMH concentration was compared among sister heifers from the same parents derived from MOET.

Plasma anti-Müllerian hormone concentrations, classification, and heifer selection

Plasma AMH concentrations of 50 JB heifers ranged from 28-1,998 $\mathrm{pg} / \mathrm{ml}$, and the mean AMH concentration $( \pm \mathrm{SD})$ was $363.5 \pm 353.3$ $\mathrm{pg} / \mathrm{ml}$. The median and 75 th percentile values of AMH concentration were 232 and $469 \mathrm{pg} / \mathrm{ml}$, respectively. The histogram of AMH concentration of each heifer and the range of AMH concentration for each group are shown in Fig. 1. Based on the criteria, the 50 heifers were classified into $\mathrm{H}(\mathrm{n}=12), \mathrm{MH}(\mathrm{n}=13)$, and $\mathrm{L}(\mathrm{n}=25)$ groups, and then selected as donors for OPU as group $\mathrm{H}(\mathrm{n}=10$ : age in months, $8.8 \pm 1.6)$, group $\mathrm{MH}(\mathrm{n}=6$ : age in months, $8.6 \pm$ $0.8)$, and group $\mathrm{L}(\mathrm{n}=9$ : age in months, $8.6 \pm 1.1)$. There were no significant differences among the ages of each group.

\section{Number of follicles by ultrasound monitoring and collected oocytes after ovum pick-up}

The age of the examined heifers during the first OPU carried out on groups $\mathrm{H}, \mathrm{MH}, \mathrm{L}$, and $\mathrm{C}$ were $412.5 \pm 18.2,418.2 \pm 19.7,402.1$ \pm 11.4 , and $412.1 \pm 49.5$, and there were no significant differences among the groups. The number of follicles determined via ultrasound examinations during OPU are shown in Fig. 2. Although the number of follicles $2-9 \mathrm{~mm}$ in diameter between the first and third OPU trials were not significantly different within each group, the mean numbers of follicles from group $\mathrm{H}$ were significantly higher $(\mathrm{P}<$ 0.05 ) than the other three groups, not only during each trial of OPU but also in terms of the average of three OPU trials.
The number of collected oocytes after OPU are shown in Fig. 3. The mean numbers of collected oocytes between the first and third OPU trials were not significantly different for each group of heifers. The mean numbers of oocytes from group $\mathrm{H}$ was significantly higher $(\mathrm{P}<0.05)$ than that of the other three groups, not only at each trial of OPU but also the average of three OPU trials. Plasma AMH concentrations was positively correlated with the total number of follicles $\left(\mathrm{R}^{2}=0.3832, \mathrm{P}<0.05\right)$ and oocytes $\left(\mathrm{R}^{2}=0.3237, \mathrm{P}<0.05\right)$ as an average of three OPU trials, as shown in Fig. 4.

\section{Comparison of anti-Müllerian hormone concentrations among} embryo-transfer-derived sister heifers

AMH concentration of sister heifers derived from the same parents by MOET is shown in Table 1. In the present study, two to five MOET-derived sister heifers were born from 10 donor cows. Although some sister heifers from the same donor parents showed similar AMH concentration (such as three heifers from donor A: 226, 271, and $373 \mathrm{pg} / \mathrm{ml}$; or two heifers from donor I: 436 and $516 \mathrm{pg} / \mathrm{ml}$ ), extremely different AMH concentration was observed among other sister heifers (such as five heifers from donor J: 35 , $161,246,271$, and $720 \mathrm{pg} / \mathrm{ml}$; or three heifers from donor F: 157, 921, and $1998 \mathrm{pg} / \mathrm{ml})$.

Recently, Hirayama et al. [12] reported that the evaluation of $\mathrm{AMH}$ concentration during the early stages is valuable for selection of candidate embryo donors in JB cattle. Therefore, in the present study, we applied the measurement to select JB donor heifers for OPU-IVP to a commercial JB herd. In the OPU-IVP system, many factors during the in vitro maturation, in vitro fertilization, and in vitro culture processes affect the blastocyst rates obtained from OPU-derived oocytes. Additionally, previous reports indicated that the number of blastocysts produced by OPU-IVP is dependent on the number of recovered oocytes $[13,14]$. Therefore, in the present study, we firstly focused on the relationship between AMH concentration and both the number of follicles and recovered oocytes. Our results 


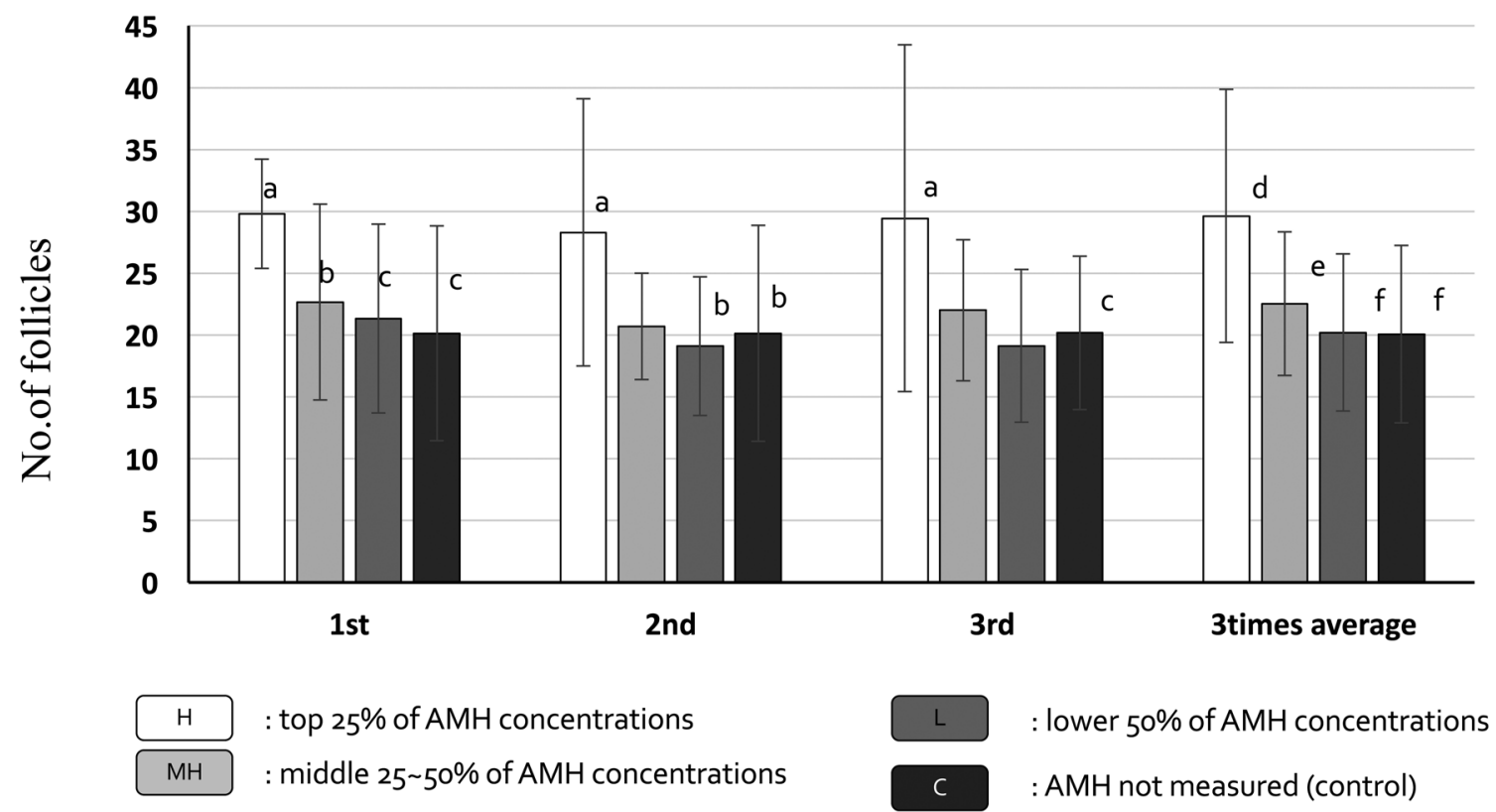

Fig. 2. Number of follicles observed by ultrasound at first and third ovum pick-up (OPU) trial, and average of three OPU trials. a-b, d-e: significant differences $(\mathrm{P}<0.05)$, a-c, d-f: significant differences $(\mathrm{P}<0.01)$

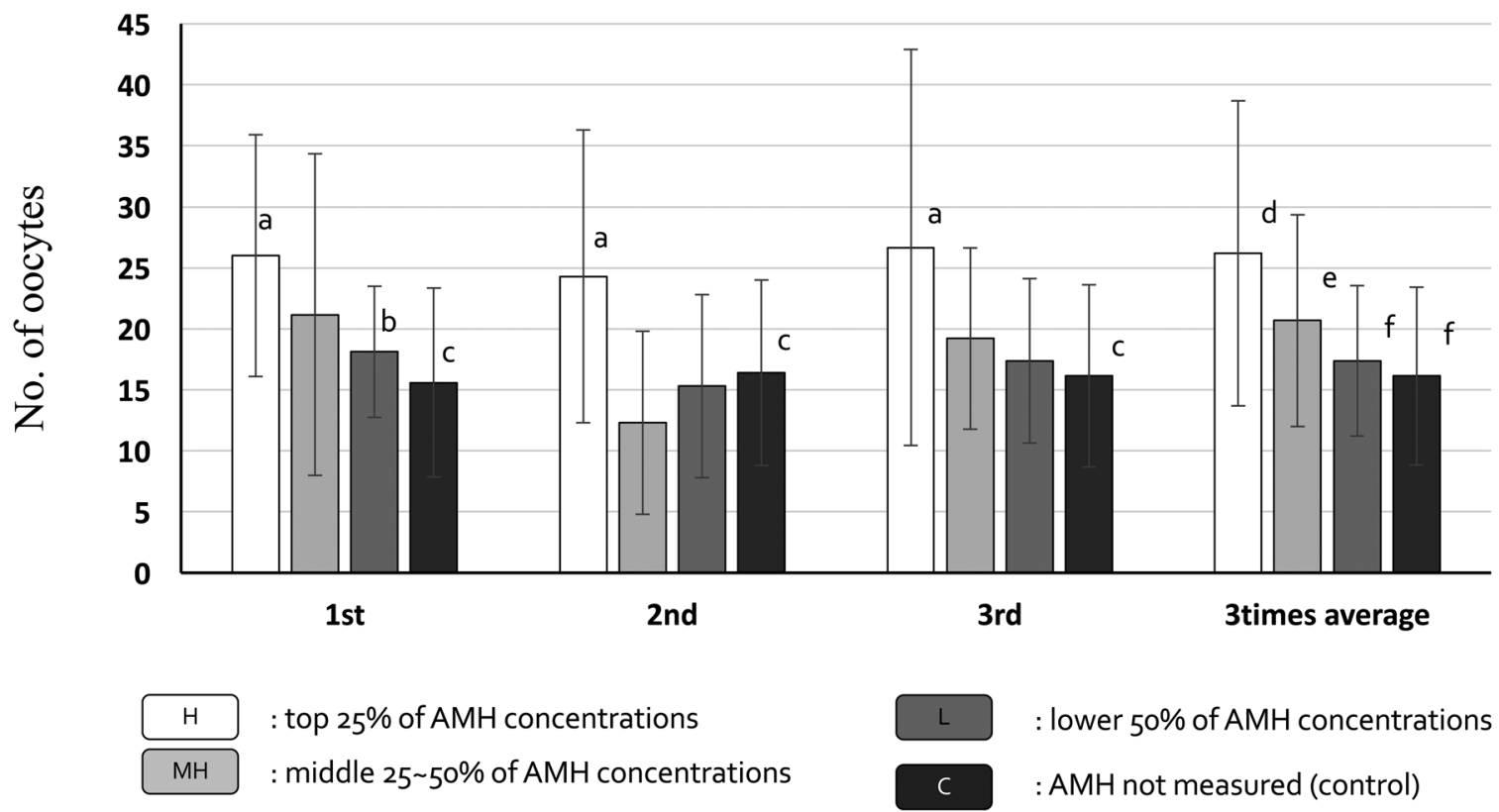

Fig. 3. Number of collected oocytes at first and third ovum pick-up (OPU) trial, and average of three OPU trials. a-b: significant differences $(\mathrm{P}<0.05)$, $\mathrm{a}-\mathrm{c}, \mathrm{d}-\mathrm{f}$ : significant differences $(\mathrm{P}<0.01), \mathrm{d}-\mathrm{e}$ : tend to significant difference $(0.05<\mathrm{P}<0.1)$

clearly indicated that the heifers with higher AMH concentration $(>$ $469 \mathrm{pg} / \mathrm{ml}$ ) measured at $7-10$ months of age had the highest numbers of follicles in their ovaries and gave the highest number of oocytes during OPU carried out at 13-15 months of age.

It has been suggested that AMH concentration is a reliable phe- notypic marker, not only for size of the ovarian reserve, ovarian function, and response to superovulation, but also for fertility and herd longevity of cattle $[5,17,18]$. Recently, in dairy cattle, it was suggested that AMH might be useful to indirectly improve predictions of the genetic merit of some reproductive traits and that there 

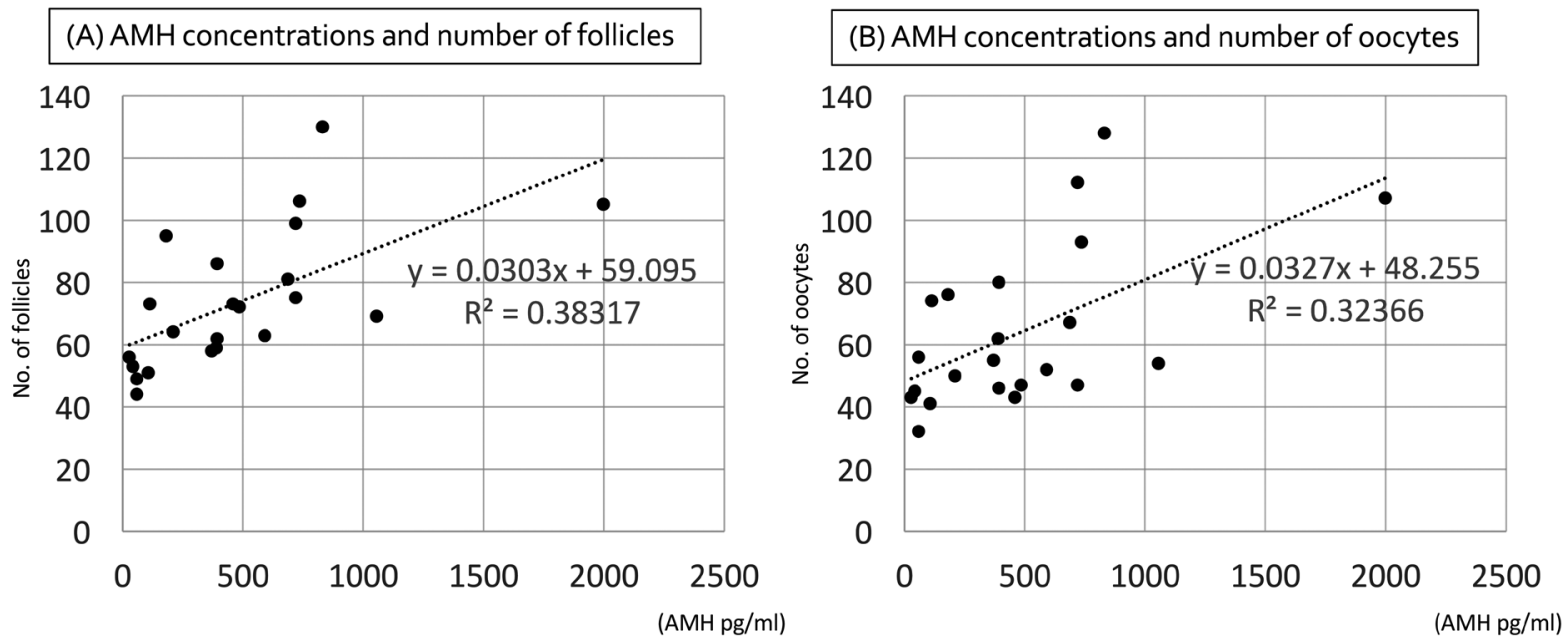

Fig. 4. (A) Correlation between total numbers of follicles and plasma anti-Müllerian hormone (AMH) concentration ( $\mathrm{n}=25$, $\mathrm{P}<0.01)$; (B) Correlation between total numbers of collected oocytes and plasma AMH concentration $(\mathrm{n}=25, \mathrm{P}<0.01)$.

Table 1. Anti-Müllerian hormone (AMH) concentrations of sister heifer derived from the same parents with multiple ovulation and embryo transfer from 10 donor cows

\begin{tabular}{|c|c|c|c|c|c|c|c|c|c|c|c|c|c|}
\hline Donor $(\mathrm{n}=10)$ & A & A & B & $\mathrm{C}$ & $\mathrm{D}$ & $\mathrm{E}$ & $\mathrm{F}$ & G & G & $\mathrm{H}$ & I & I & $\mathrm{J}$ \\
\hline Father $(n=6)$ & $\mathrm{a}$ & $\mathrm{b}$ & $\mathrm{c}$ & $\mathrm{d}$ & $\mathrm{b}$ & $\mathrm{e}$ & $\mathrm{f}$ & a & $\mathrm{f}$ & $\mathrm{a}$ & $\mathrm{a}$ & $\mathrm{e}$ & $f$ \\
\hline No. of sister heifers & 2 & 3 & 4 & 3 & 2 & 2 & 3 & 2 & 4 & 2 & 2 & 2 & 5 \\
\hline \multirow{5}{*}{$\begin{array}{l}\text { AMH concentration }(\mathrm{pg} / \mathrm{ml}) \\
\text { of each sister heifers }\end{array}$} & 133 & 226 & 165 & 124 & 185 & 193 & 157 & 201 & 184 & 71 & 61 & 436 & 35 \\
\hline & 593 & 271 & 226 & 335 & 395 & 1057 & 921 & 689 & 401 & 395 & 197 & 516 & 161 \\
\hline & & 373 & 833 & 462 & & & 1998 & & 722 & & & & 246 \\
\hline & & & 973 & & & & & & 738 & & & & 271 \\
\hline & & & & & & & & & & & & & 720 \\
\hline
\end{tabular}

may be a possible relationship between AMH concentration and superovulatory traits in dairy cattle [18]. Additionally, regarding the application of AMH concentration for OPU trials, previous reports also considered $\mathrm{AMH}$ to be a reliable endocrine marker of the number of ovulations and embryos produced in response to superovulation or through OPU-IVP [5,9-11]. In the present study, measurement of AMH from each heifer was once carried out when rectal palpation of the heifer was difficult because of their body size and at the time when owner's make decisions regarding the fate of the heifers. It has been reported that plasma AMH concentration in JB cows ranged from $0.032-1.992 \mathrm{ng} / \mathrm{ml}$, and mean \pm SD was $0.334 \pm$ 0.318 [12]. In the present study, although the age of the heifer when blood was sampled was different to that of the heifers tested in the previous report, the AMH concentration was almost within the same range, and the average was almost similar. Therefore, although it was suggested that animal breed and age represented major factors influencing AMH concentration in cattle $[14,19]$, our results suggest a general AMH concentration for JB cattle.

In the present study, we used the median and 75 th percentile values of $\mathrm{AMH}$ concentration for classification of 50 heifers according to the previous report which was evaluated the superovulatory response of JB cattle [12]. Although we used the classification methods for evaluating both the number of follicles and collected oocytes after OPU trials of JB heifers, our results clearly indicated that were significant differences for both parameters among each classified group. Our results may indicate that the classification method for heifers by a single measurement of AMH concentration is useful for selecting OPU-donor heifers for herd breeding programs.

Rico et al. [20] reported that the measurements of plasma AMH concentration before each repetition of the OPU protocol were highly repeatable over a one-year period, similar to counts of the number of follicles that developed after treatment and were available for follicular puncture. In agree with the previous report, our results also reconfirm a strong within-animal repeatability in the numbers of both follicles and oocytes in 13-15 months old JB heifers, for at least three repeats of the OPU trials.

In the present study, among the 50 examined heifers, two to five MOET-derived sister heifers were produced from 10 donor cows using the frozen semen of six bulls. Interestingly, although some sister heifers from the same donor parents had similar AMH concentrations, extremely different AMH concentrations were observed among other sister heifers under the same nutritional conditions. Studies have indicated that AMH concentration is highly variable among individuals, and that the factors affecting ovarian reserves (indirectly 
affecting circulating AMH concentration) may be maternal nutrition, diseases and the presence of endocrine disrupters during pregnancy $[5,19,21]$. Therefore, our results regarding the differences observed among heifers within each family may strongly support these previous reports. Nevertheless, we propose the exclusion of dietary feed as a factor affecting ovarian reserves and instead add as factors genetic differences between sisters, environmental differences related to the nutritional conditions, and low appetite of the recipient cows/ heifers when affected by disease. Moreover, our results suggest that the environmental management of recipient cows/heifers, including nutritional control and disease prevention, is important for improving the breeding ability of the herd.

In conclusion, the present study revealed that a single measurement of plasma AMH concentration at 7-10 months old could be an efficient method for selecting donor heifers for OPU or superovulation. It would therefore accelerate the intensive breeding of JB herds. Additionally, our results may reconfirm that $\mathrm{AMH}$ concentrations in JB heifers is highly variable among individuals, and that the factors that indirectly affect AMH concentration may be maternal nutrition, disease, and the presence of endocrine disrupters during pregnancy.

\section{Methods}

The experiments were conducted according to the regulations concerning the protection of experimental animals and the guidelines of Yamaguchi University, Japan (No.40, 1995, approval date 27 March 2017).

\section{Animals and blood sampling}

The experiment was carried out with $50 \mathrm{JB}$ heifers (mean $\pm \mathrm{SD}$, $8.7 \pm 0.7$ age in months; range: $7.3-10.2$ months-old) that were held at a commercial farm in Hokkaido, Japan, from October 2016 to August 2017. They were all born at the same farm derived from a MOET program, and their mothers, recipient F1 heifers, were held in the same environment and provided the same feed (roughage: $10.5 \mathrm{~kg}$; dent-corn silage: $1 \mathrm{~kg}$; concentrate $3.3 \mathrm{~kg}$; and calculated required minerals) during their pregnancy. Venous blood samples for AMH measurement were collected once from heifers immediately prior to the owner's decision regarding whether the heifer will become an egg donor or be sent to the market. After collection in silicone-coated tubes, the blood samples were centrifuged at 3000 $\times g$ for 10 min to recover the plasma, which was stored at $-20^{\circ} \mathrm{C}$ until the AMH assays were carried out.

\section{Measurement of plasma anti-Müllerian hormone concentration and classification of the heifers}

Plasma AMH concentration was measured within 7 days of collection with a Bovine AMH ELISA kit (AnshLabs, TX, USA) according to the previous report [15]. Undiluted plasma $(50 \mu \mathrm{l})$ was used for the assay, and the assay had a limited detection of $11 \mathrm{pg} / \mathrm{ml}$ and a coefficient of variation of 2.9 according to the manufacturer's instructions. Based on AMH concentration, animals were divided into three groups as follows: group $\mathrm{H}$ contained those with the highest $25 \%$, group $\mathrm{MH}$ contained those with the next $25 \%$, and group $\mathrm{L}$ contained those with the lowest $50 \%$ of AMH concentration. Then, 10 out of 12 of group $\mathrm{H}$, six out of 13 of group $\mathrm{MH}$, and nine out of 25 of group L animals were selected to be held at the farm as donors for OPU. The other 25 animals were sold on the market. Although the AMH concentration of the heifers of group L was low, they were selected under the conventional evaluation criteria to be used as donors, specifically based on growth, pedigree, and temper. In the present study, 84 heifers without measured plasma $\mathrm{AMH}$ concentration were included in the control (group C) for the OPU trials.

\section{Hormone and ovum pick-up treatments and evaluation of cumulus-oocyte complexes}

At $13-15$ months of age, OPU was carried out on the 25 selected heifers three times every 2 weeks by three skilled technicians. Before OPU treatment, the synchronization of follicular waves of each heifer was performed with controlled internal drug release device (CIDR, Pfizer Japan, Tokyo, Japan) insertion and GnRH (100 $\mu \mathrm{g} / \mathrm{heifer}$, Conceral 100, InterVet, Tokyo, Japan) administration concurrently to induce ovulation of all large follicles present in the ovary at Day 1. Three days after insertion, administration of FSH (10 AU/heifer, Antorin R-10, Kyoritsu Seiyaku, Tokyo, Japan) administered twice daily in decreasing doses over 2 days (4 days: AM, PM, 3 AU; 5 days: AM, PM, 2 AU). At 6 days, OPU was carried out $12 \mathrm{~h}$ after the last FSH administration after removal of the CIDR.

The number of follicles were determined via ultrasound examination immediately prior to oocyte aspiration, and the number of follicles 2-9 $\mathrm{mm}$ in diameter were counted. Follicular aspiration was performed using an ultrasound-guide transvaginal aspiration system (HS-2200V, FHK, Tokyo, Japan) equipped with a disposal 18-G single-lumen sterile needle using $70-80 \mathrm{mmHg}$ of suction pressure. The follicles were aspirated into a tube containing a Ringer's lactate solution (ZENOAQ; Fukushima, Japan) supplemented with heparin (10 IU/ $\mathrm{ml}$; Ajinomoto, Tokyo, Japan) and $0.5 \%$ fetal bovine serum. The cumulus-oocyte complexes (COCs) were evaluated immediately following aspiration as per the method of de Loos et al. [16]. COCs with several layers of cumulus cells and homogeneous oocyte cytoplasm were classified into grade 1, while those with one to three layers of cumulus cells, completely denuded oocytes, expanded cumulus cells, and degenerated oocytes were classified into grades 2, 3, 4, and 5 , respectively. After evaluation, only the numbers of grades 1 and 2 COCs were recorded as collected oocytes and the results were compared within and among the groups.

\section{Statistical analysis}

All results are presented as means $\pm \mathrm{SD}$. Data were analyzed using Student's $t$-test or one-way ANOVA followed by post-hoc test for comparisons between means. For all analyses, $\mathrm{P}<0.05$ was considered as significant.

\section{References}

1. Guerreiro BM, Batista EOS, Vieira LM, Sá Filho MF, Rodrigues CA, Castro Netto A, Silveira CRA, Bayeux BM, Dias EAR, Monteiro FM, Accorsi M, Lopes RNVR, Baruselli PS. Plasma anti-mullerian hormone: an endocrine marker for in vitro embryo production from Bos taurus and Bos indicus donors. Domest Anim Endocrinol 2014; 49: 96-104. [Medline] [CrossRef]

2. Hirata T, Sato M, Sasaki S, Sasaki O, Osawa T. Effect of suckling on embryo production by repeated ovum pick-up before and after timed artificial insemination in early 
postpartum Japanese black cows. J Reprod Dev 2008; 54: 346-351. [Medline] [CrossRef]

3. Hirayama H, Kageyama S, Naito A, Fukuda S, Fujii T, Minamihashi A. Prediction of superovulatory response in Japanese Black cattle using ultrasound, plasma anti-Müllerian hormone concentrations and polymorphism in the ionotropic glutamate receptor AMPA1/ GRIA1. J Reprod Dev 2012; 58: 380-383. [Medline] [CrossRef]

4. Takuma T, Sakai S, Ezoe D, Ichimaru H, Jinnouchi T, Kaedei Y, Nagai T, Otoi T. Effects of season and reproductive phase on the quality, quantity and developmental competence of oocytes aspirated from Japanese black cows. J Reprod Dev 2010; 56: 55-59. [Medline] [CrossRef]

5. Ireland JJ, Smith GW, Scheetz D, Jimenez-Krassel F, Folger JK, Ireland JL, Mossa F, Lonergan P, Evans AC. Does size matter in females? An overview of the impact of the high variation in the ovarian reserve on ovarian function and fertility, utility of anti-Müllerian hormone as a diagnostic marker for fertility and causes of variation in the ovarian reserve in cattle. Reprod Fertil Dev 2011; 23: 1-14. [Medline] [CrossRef]

6. Silva-Santos KC, Santos GMG, Koetz Júnior C, Morotti F, Siloto LS, Marcantonio TN, Urbano MR, Oliveira RL, Lima DCM, Seneda MM. Antral follicle populations and embryo production - in vitro and in vivo - of Bos indicus-taurus donors from weaning to yearling ages. Reprod Domest Anim 2014; 49: 228-232. [Medline] [CrossRef]

7. La Marca A, Volpe A. Anti-Müllerian hormone (AMH) in female reproduction: is measurement of circulating AMH a useful tool? Clin Endocrinol (Oxf) 2006; 64: 603-610. [Medline] [CrossRef]

8. Monniaux D, Clemente N, Touzé JL, Belville C, Rico C, Bontoux M, Picard JY, Fabre S. Intrafollicular steroids and anti-mullerian hormone during normal and cystic ovarian follicular development in the cow. Biol Reprod 2008; 79: 387-396. [Medline] [CrossRef]

9. Rico C, Fabre S, Médigue C, di Clemente N, Clément F, Bontoux M, Touzé JL, Dupont M, Briant E, Rémy B, Beckers JF, Monniaux D. Anti-mullerian hormone is an endocrine marker of ovarian gonadotropin-responsive follicles and can help to predict superovulatory responses in the cow. Biol Reprod 2009; 80: 50-59. [Medline] [CrossRef]

10. Rico C, Médigue C, Fabre S, Jarrier P, Bontoux M, Clément F, Monniaux D. Regulation of anti-Müllerian hormone production in the cow: a multiscale study at endocrine, ovarian, follicular, and granulosa cell levels. Biol Reprod 2011; 84: 560-571. [Medline] [CrossRef]

11. Monniaux D, Barbey S, Rico C, Fabre S, Gallard Y, Larroque H. Anti-Müllerian hormone: a predictive marker of embryo production in cattle? Reprod Fertil Dev 2010; 22: 1083-1091. [Medline] [CrossRef]
12. Hirayama H, Naito A, Fukuda S, Fujii T, Asada M, Inaba Y, Takedomi T, Kawamat M, Moriyasu S, Kageyama S. Long-term changes in plasma anti-Müllerian hormone concentration and the relationship with superovulatory response in Japanese Black cattle. J Reprod Dev 2017; 63: 95-100. [Medline] [CrossRef]

13. Merton JS, de Roos APW, Mullaart E, de Ruigh L, Kaal L, Vos PLAM, Dieleman SJ. Factors affecting oocyte quality and quantity in commercial application of embryo technologies in the cattle breeding industry. Theriogenology 2003; 59: 651-674. [Medline] [CrossRef]

14. Ghanem N, Jin JI, Kim SS, Choi BH, Lee KL, Ha AN, Song SH, Kong IK. The antiMüllerian hormone profile is linked with the in vitro embryo production capacity and embryo viability after transfer but cannot predict pregnancy outcome. Reprod Domest Anim 2016; 51: 301-310. [Medline] [CrossRef]

15. Cardoso CJT, de Oliveira JS Junior, Kischel H, da Silva WAL, da Silva Arruda ED, Souza-Caceres MB, de Oliveira FAM, Nogueira E, de Paula Nogueira G, MeloSterza FdA. Anti-Müllerian hormone (AMH) as a predictor of antral follicle population in heifers. Anim Reprod 2017; 15: 12-16. [CrossRef]

16. de Loos F, van Vliet C, van Maurik P, Kruip TA. Morphology of immature bovine oocytes. Gamete Res 1989; 24: 197-204. [Medline] [CrossRef]

17. Ribeiro ES, Bisinotto RS, Lima FS, Greco LF, Morrison A, Kumar A, Thatcher WW, Santos JE. Plasma anti-Müllerian hormone in adult dairy cows and associations with fertility. J Dairy Sci 2014; 97: 6888-6900. [Medline] [CrossRef]

18. Nawaz MY, Jimenez-Krassel F, Steibel JP, Lu Y, Baktula A, Vukasinovic N, Neuder L, Ireland JLH, Ireland JJ, Tempelman RJ. Genomic heritability and genome-wide association analysis of anti-Müllerian hormone in Holstein dairy heifers. J Dairy Sci 2018; 101: 8063-8075. [Medline] [CrossRef]

19. Mossa F, Jimenez-Krassel F, Scheetz D, Weber-Nielsen M, Evans ACO, Ireland JJ. Anti-Müllerian Hormone (AMH) and fertility management in agricultural species. Reproduction 2017; 154: R1-R11. [Medline] [CrossRef]

20. Rico C, Drouilhet L, Salvetti P, Dalbiès-Tran R, Jarrier P, Touzé JL, Pillet E, Ponsart C, Fabre S, Monniaux D. Determination of anti-Müllerian hormone concentrations in blood as a tool to select Holstein donor cows for embryo production: from the laboratory to the farm. Reprod Fertil Dev 2012; 24: 932-944. [Medline] [CrossRef]

21. Monniaux D. Factors influencing establishment of the ovarian reserve and their effects on fertility. In: Proceeding of the $10^{\text {th }}$ International Ruminant Reproduction Symposium (IRRS 2018); 2018; Brazil. Anim Reprod 15 (Suppl. 1); 635-647. 